\title{
Nebulised bronchodilators, antibiotics and rhDNase for children with cystic fibrosis
}

\author{
D A Spencer
}

Bronchodilators

Nebulised bronchodilators are used extensively in children with cystic fibrosis, but in many instances this use is not yet based on objective evidence of clinical benefit.

MODES OF ACTION

The main effect of bronchodilators is probably to reduce smooth muscle spasm in the airways of patients with cystic fibrosis. In addition, improved mucociliary clearance has been shown in vivo following subcutaneous adshown in vivo following subcutaneous ad-
ministration of terbutaline to adults with cystic ministration of terbutaline to adults with cystic ${ }^{1}$ and also, theoretically, $\beta$ agonists might reduce inflammatory damage. ${ }^{2}$ The relative importance of these mechanisms and their clinical relevance are unknown.

The occurrence of reversible airways obstruction in children with cystic fibrosis is largely a reflection of the frequency of asthma in the whole paediatric population (perhaps $15 \%)$, as well as an increase in bronchial responsiveness secondary to the complex chronic inflammation present in their airways. ${ }^{3}$ Over a third of patients with cystic fibrosis will show evidence of reversible airways obstruction at some time, but the response in individuals is extremely variable. ${ }^{4-6}$ The interpretation of these results is hampered by poor reproducibility of pulmonary function measurements. $^{7}$ In view of this variability a therapeutic trial of regular $\beta$ agonists is appropriate in children with cystic fibrosis who wheeze, or in cases where there is a marked improvement in symptoms or pulmonary function following a test dose. ${ }^{8}$ The routine use of methacholine challenge is not recommended. It is not known whether the responses to $\beta$ agonists or anticholinergic agents vary with age.

DRUGS

Ipratropium bromide has been shown to cause bronchodilatation when given to children and adults with cystic fibrosis. ${ }^{910}$ In a separate study in children there was no evidence of acute bronchodilatation with either salbutamol or ipratropium but a reduction in bronchial reactivity to methacholine was demonstrated. ${ }^{11}$ It has been suggested that the combination may be more effective than either agent alone, ${ }^{12}$ although this finding was not confirmed in another study. ${ }^{10}$ Anticholinergic agents have not been used extensively in children with cystic fibrosis in the UK, probably because of concerns (unverified) that they might increase sputum viscosity. There is a single report in the literature of distal intestinal obstruction syndrome occurring in association with ipratropium. ${ }^{13}$

Optimal dosage regimens for $\beta$ agonists have not been investigated, and doses given to children with cystic fibrosis are usually similar to those used in asthma. It has been suggested that these doses should be calculated according to body weight, ${ }^{14}$ but whether this refinement is of any practical significance in cystic fibrosis is unknown.

If a decision has been made to give inhaled bronchodilators to a child with cystic fibrosis, selection of the mode of administration deserves careful consideration because the time and effort taken to deliver nebulised bronchodilators is of critical importance if other dilators is of critical importance if other
nebulised treatments such as antibiotics and rhDNase are prescribed concurrently. Mixing of antibiotics and rhDNase in the same nebuliser chamber is not recommended ${ }^{15}$ and an interval of 30 minutes should be allowed between giving these two medications. Such reween giving these two medications. Such reginens are onerous and to allow children to follow a near normal lifestyle it is imperative to avoid giving nebulised bronchodilators when administration by hand held inhalers would be equally effective.

\section{Antibiotics}

The use of nebulised antibiotics is discussed in detail in the paper by Webb and Dodd on pp S69-71. Here the use of nebulised antibiotics is considered specifically in relation to paediatric practice.

The study by Valerius et $a l^{16}$ demonstrated that chronic colonisation with Pseudomonas aeruginosa in patients with cystic fibrosis could be delayed by the use of oral ciprofloxacin and nebulised colistin. Longer term studies are required to determine the duration of benefit and whether repeated courses of treatment are beneficial or whether $P$ aeruginos $a$ is isolated again at a later date.

Pseudomonas aeruginosa is usually first isolated from patients in childhood. At this time there is often significant acute or subacute clinical deterioration with an increase in respiratory symptoms, weight loss or a failure to gain weight, new clinical signs, or a reduction in pulmonary function. Under these circumstances it is usual practice at the author's centre to give a two week course of parenteral antipseudomonal antibiotics as well as nebulised colistin.

There have been no published studies to investigate whether oral ciprofloxacin or nebulised colistin alone are as effective as a combination. In addition, it is
Cardiothoracic Centre,
Freeman Hospital, Newcastle upon Tyn 
long to continue nebulised colistin in patients without new symptoms, or whether it may be advantageous to remain on this medication indefinitely in view of the poorer prognosis associated with chronic infection. ${ }^{17}$

Similarly, it is not yet known whether initiating treatment with long term nebulised antipseudomonal antibiotics at the time of diagnosis may delay or prevent the onset of colonisation.

PRACTICAL ASPECTS

A face mask should be used instead of a mouthpiece in infants and younger children who will not tolerate one. Nasal deposition of drugs may be less important in this age group than in adults. ${ }^{18} \mathrm{~A}$ lower flow compressor with an active Venturi system is preferred for children.

\section{rhDNase}

Treatment of cystic fibrosis with nebulised rhDNase is considered in detail in the paper by Conway and Watson on pp S64-68. The following discussion concerns particular aspects relevant to children.

rhDNase administered by nebuliser in a dose of $2.5 \mathrm{mg}$ once daily to patients with cystic fibrosis with moderately severe suppurative lung disease results in a small but significant improvement in pulmonary function with a mean increase of about $6 \%$ in forced expiratory volume in one second. ${ }^{19-21}$ The onset of benefit is rapid and appears to be maintained for the duration of treatment, at least up to 24 weeks. ${ }^{2}$ Pulmonary function returns to the previous baseline within 48 hours of discontinuance. Treatment appears to be safe, with the only consistent adverse effect being mild pharyngitis. Longer term treatment is associated with a very small reduction in the likelihood of patients requiring intravenous antibiotics. ${ }^{22}$ As pulmonary function predicts mortality in patients with cystic fibrosis, ${ }^{23}$ it can be expected that this treatment might lead to an increased life expectancy but there have, as yet, been no long term studies to examine this.

PATIENT ELIGIBILITY

The only published data available are for patients with moderately severe suppurative disease with a forced vital capacity of $>40 \%$ predicted. One report suggests that a similar degree of benefit is obtained in patients with more severe disease ${ }^{24}$ but that the time taken to achieve a plateau is longer.

There are no available data on the use of rhDNase in children under five years or in older children with clinically mild disease, and as yet there is no evidence to support the use of rhDNase as a prophylactic agent in use of rhDNase as a prophylactic agent in
preventing the onset of suppurative lung disease.

PRACTICAL ASPECTS

The cost of rhDNase treatment has prompted early publication of guidelines both in the
$\mathrm{USA}^{25}$ and the UK, ${ }^{26}$ even though data with which to formulate them are scanty. These guidelines, however, are not intended to be proscriptive and it is emphasised that patients with a broad spectrum of pulmonary disease may benefit. The UK guidelines suggest that patients likely to benefit would fulfil the following criteria: (1) aged over five years; (2) have purulent sputum or, in young children, a productive cough; (3) have had more than one exacerbation of respiratory infection requiring intravenous antibiotics in the last 12 months; (4) a forced vital capacity of $<80 \%$ predicted for height when in a stable state; and (5) be compliant with previous treatments.

It is recommended that treatment should be initiated under the direct supervision of a cystic fibrosis specialist. Most children with moderate suppurative disease can be managed as outpatients but those with severe or unstable disease may be better beginning treatment as an inpatient under the close supervision of a cystic fibrosis physiotherapist.

The recommended starting dose is $2.5 \mathrm{mg}$ once daily. Occasional patients may benefit from an increase to $2.5 \mathrm{mg}$ twice daily, but there is no evidence of any further benefit from a larger daily dose. Only $30 \%$ of patients treated will have a statistically significant improvement in pulmonary function ${ }^{27}$ and a therapeutic trial is necessary in each case. The optimal duration of such a trial is uncertain. Although most patients with moderately severe disease show a response within 14 days, children with more severe disease may require a trial of up to, perhaps, three months.

The current guidelines ${ }^{2526}$ assess outcome mainly in terms of improvement in pulmonary function. They take no account of subjective benefits and improved well being resulting from easier expectoration of sputum and there is, as yet, no published information on quality of life. As cystic fibrosis can be a severely debilitating condition in children, such data are urgently required to enable the use of rhDNase to be justified if subjective benefit can be to be justified if subjective benefit can be demonstrated even in the absence of changes in lung function.

rhDNase is not licensed for use in children under the age of five years because of limited data on its use in this age group. Nevertheless,

it is likely that some young children with suppurative lung disease will benefit, although this purative lung disease wi cause of the problem of obtaining reliable pulmonary function measurements.

1 Wood RE, Wanner A, Hirsch J, Farrell PM. Tracheal mucociliary transport in patients with cystic fibrosis and its
stimulation by terbutaline. Am Rev Respir Dis 1975;111:

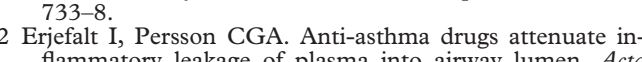
3 Warner JO. Immunology of cystic fibrosis. Br Med Bull 1992;48: 893-911.

Pattishall EN. Longitudinal response of pulmonary function
to bronchodilators in cystic fibrosis. Pediatr Pulmonol 1990 to bronc.
$\mathbf{9}: 80-5$.

5 Eggleston PA, Rosenstein BJ, Stackhouse CM, Mellits D, dilator therapy in cystic fibrosis. Chest 1991; 99 : 1088-92. 6 Landau LI, Phelan PD. The variable effect of a bronchodilating agent on pulmonary function in cystic fibrosis. $\mathcal{F}$ 
7 Cooper PJ, Robertson CG, Hudson IL, Phelan PD. VariPulmonol 1990;8:16-22.
Fiel SB. Clinical 8 Fiel SB. Clinical management of pulmonary disease in cystic 9 Sanchez I, De Koster J, Holbrow J, Chernick V. The effect of high doses of inhaled salbutamol and ipratropium brom-
ide in patients with stable cystic fibrosis. Chest 1993;104:

10 Weintraub SJ, Eschenbacher WL. The inhaled bronchodilators ipratropium bromide and metaproteronol in adults

with cystic fibrosis. Chest 1989;95:861-4.
11 Avital A, Sanchez I, Chernick V. Efficacy of salbutamol and ipratropium bromide in decreasing bronchial reactivity in 34-7.
Sanchez I, Holbrow J, Chernick V. Acute bronchodilato response to a combination of beta-adrenergic and anti1992;120:486-8. 3 Mulhern D, Fitzgerald MX. Meconium ileus equivalent in
association with nebulized ipratropium bromide in cystic Sly PD, Le Souef PN. Inhaled therapy in paediatrics. $\mathcal{F}$ Paediatr Child Health 1991;27:7-10. 15 Cipolla D, Clark A, Pearlman R, Rosen R, Gonda I. Pul-
monozyme rhDNase should not be mixed with other nebulizer medications. Pediatr Pulmonol 1994;10(Suppl): 207
Valerius NH, Koch C, Hoiby N. Prevention of chronic fibrosis by

17 Hoiby N, Flensborg EW, Beck B, Friis B, Jacobsen SV, Jacobsen L. Pseudomonas aeruginosa infection in cystic
fibrosis. Scand 9 Respir Dis 1977;58:65-79.3.
18 O'Callaghan C. How to get drugs into the respiratory tract. Arch Dis Child 1993;68:441-3.
19 Hubbard RC, McElvaney NG, Birrer P, Shak S, Robinson , Jolley C. A preliminary study of aerosolized reof cystic fibrosis. N Engl F Med 1992:326:812-5. 20 Ramsey BW, Astley SJ, Aitken ML, Burke W, Colin AA, Dinistration. Ef aery and safety ministration of aerosolized recombinant human de-
oxyribonuclease in patients with cystic fibrosis. Am Rev Respir Dis 1993;148: 145-51.
Ranasinha C, Assouf B, Shak S, Christiansen D, Fuchs Ranasinha C, Assoufi B, Shak S, Christiansen D, Fuchs
H, Empey D, et al. Efficacy and safety of short-term Idministration of aerosolised recombinant human DNase Fuchs HJ Borowitz DS, Christiansen DH, Morris EM, Nash ML, Ramsey BW. Effect of aerosolized recombinan

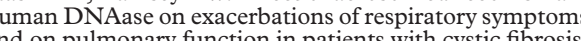
and on pulmonary function in patients with cystic fibrosis. Kerem $\mathrm{E}$, Reisman $\mathrm{J}, \mathrm{C}$ Corey $\mathrm{M}$, Canny GJ, Levison $\mathrm{H}$.
Prediction of mortality in patients with cystic fibrosis. $N$ Engl F Med 1992;326:1187-91.
Johnson C. A multicenter, double-blind, placebo-controlled study to evaluate the safety and efficacy of aerosolized dvanced lung disease. Pediatr Pulmonol 1994;10 (Suppl): S8.2. BW, Dorkin HL. Consensus conference: practical
applications of Pulmozyme. Pediatr Pulmonol 1994;17: 404-8.
Cystic Fibrosis Trust. Guidelines for the treatment of cystic fibrosis [CF] with dornase alpha [Pulmozyme]. London 27 Davis PB. Evolution of therapy for cystic fibrosis. N Engl f
Med 1994;331:672-3. 